Dhaka Univ. J. Biol. Sci. 24(1): 43-52, 2015 (January)

\title{
DEVELOPMENTAL STAGES OF LAMPIDES BOETICUS (LEPIDOPTERA:LYCAENIDAE) AND THEIR ASSOCIATION WITH THE HOST PLANT LUPINUS NANUS (FABACEAE)
}

\author{
Md. Kowser Miah*, Sajeda Akand, Nousheen Parven and M.A. Bashar \\ Environmental Biology and Biodiversity Laboratory (EBBL), Department of Zoology, \\ University of Dhaka, Dhaka-1000, Bangladesh
}

Key words: Developmental stage, Larval instar, Plant phenology, Synchronization

\begin{abstract}
Developmental stages in the life cycle of lycaenid butterfly, Lampides boeticus (Lepidoptera : Lycaenidae) and their association with the host plant (Lupinus nanus) (Fabaceae) were examined both in the laboratory under $29 \pm 3^{\circ} \mathrm{C}$ temperature with $\mathrm{RH} 78 \pm 2 \%$ and field conditions. The oviposition behaviour, incubation and larval-pupal period of the butterfly and its association with $L$. nanus were studied. The host plant association and duration of developmental stages were given importance. Duration of life cycle (egg to adult) was 19 - 21 days. Eggs, four larval instars and pupal stages were distinct. Lampides boeticus was found deeply associated with L. nanus to complete its life cycle. This association with host plant was characterized and evidenced by the use of host leaves, flowers, buds and seeds ( pods) both in the larval (11 - 13 days) and pupal (4 - 6 days) stages. The incubation period, different larval instars and pupal stage were found to be associated deeply with the phenological phases of the host plant.
\end{abstract}

\section{Introduction}

Butterflies are ideal subjects for ecological study in landscapes and act as bioindicators of the environments ${ }^{(1,2)}$. These are particularly sensitive to environmental variations $^{(3)}$. Seven families of butterflies are found in Bangladesh, viz. Papilionidae, Pieridae, Nymphalidae, Danaidae, Satyridae, Lycaenidae and Hesperidae(4). Under Lycaenidae the blues (Polyommatinae), coppers (Lycaeninae) and hairstreaks (Theclinae) butterflies are very common in the country(5). Positive relations have been found between butterflies diversity and its host plant diversity, habitat complexity, landscape structure, topographic and moisture gradients and climate ${ }^{(6,7)}$. The diversity of butterflies decreases day by day due to the loss of forest ecosystem and plant diversity ${ }^{(8)}$. Butterflies are considered to be opportunistic foragers that visit a wide variety of available flowers $(9,10)$. Majority of them are host specific and have close relationship with their host plants ${ }^{(11)}$. Various behavioural aspects, such as foraging, resting, flying, mating and egg laying of

*Author for correspondence: <mmkowser@yahoo.com>. 
lycaenid butterflies are associated with plants. The biology of these butterflies are associated with the specific host-plants(12). They utilize various plant species under Leguminosae for maintaining their developmental stages ${ }^{(13)}$. The choice of host plants as nectar sources by the lycaenids depends on innate colour preferences ${ }^{(14)}$. Different generations may change their preferences of host plants due to seasonal variations ${ }^{(15)}$. The present experiment has been emphasized on the identification of the life stages of Lampides boeticus and its association with Lupinus nanus (host plant).This theme was undertaken with a view to analyzing the host plant association at different developmental stages that could be utilized as a tool for butterfly colonization in the forest ecosystem.

\section{Materials and Methods}

The study was conducted in the Environmental Biology and Biodiversity Laboratory (EBBL), Department of Zoology, University of Dhaka and in the Germplasm Centre (GPC) of Zoological Garden from July, 2009 to June, 2010.

The stem of young leaves, buds, flowers and seeds (pods) of L. nanus and the eggs, larvae, pupae of $L$. boeticus were collected from the GPC. The samples were collected once in a week during the study period.

Females were observed to lay eggs on the host plant L. nanus at day light. The egg laying behaviour was observed following the methods described by Jermy and Szentesi ${ }^{(16)}$.

The laid eggswere collected by cutting the host plant stems at $45^{\circ}$ angular areas. After cutting the stem, it was wrapped with wetted cotton to make the stem alive. It was set up into a glass bottle which was filled with water. The bottle with the stem was placed into a larvae-rearing cage. The incubation period was observed by following the methods used by Bashar et al.(17).

Larvae were reared in three-layered plastic cages. The length, width and height of the 1st layer were 362.5, 300, $150 \mathrm{~mm}$, respectively; the 2nd layer were 350, 287.5, 150 $\mathrm{mm}$, respectively and 3rd layer were 350, 287.5 and $62.5 \mathrm{~mm}$, respectively. Two pieces of cork-sheet were fixed to provide space between 1st and 2nd layers. The 2nd layer was perforated to pass air and maintain proper humidity.

The larvae of different instars were measured by using a millimeter scale. The old plant-parts used for feeding were replaced by fresh leaves, shoots, buds and pods. The larvae were replaced in a new shoot of the host plant. A hairy soft brush was used to clean cages and maintain a proper environment for larval rearing and avoiding unhygienic condition. The larval period of an instar is recorded between the time of first larval appeared and the larvae first moulted of the next instar with changes of morphological characteristics. Larvae were reared following the method of Zalocki 
et al.(18) and their feeding potential was measured according to the method used by Singh(19).

Pupae were kept in an adult emergence cabinet which was rectangular in shape with $525 \mathrm{~mm}$ long, $450 \mathrm{~mm}$ wide and $648 \mathrm{~mm}$ high, and made with iron rods. The cabinet was covered by muslin net to prevent the emerged butterfly from escaping. There was a zipper in this net for entry and exit of the pupal cage to observe. After the emergence of the adult butterfly it was preserved in the laboratory for further study. The pupal stages of the butterfly were studied following the method of Baker ${ }^{(20)}$.

The biology of butterfly was studied according to Rao et al.(21) and Hill(22). The identification of butterflies was done following the methods of Borror et al.(23) and Bingham et al. (24).

The soil was prepared at Germplasm Centre (GPC) to sow the seeds of L. nanus which were collected from the Butterfly Research Park (BRP), Gazipur. The seeds were sowed at a $30.48 \mathrm{~cm} \times 30.48 \mathrm{~cm}$ seed bed. The germinating duration, vegetative growth, budding condition and fruitification stages were observed following the methods of Pandey (25).

\section{Results and Discussion}

The different developmental stages, viz. egg, larva, pupa and adult of lycaenidbutterfly, L. boeticus were characteristically associated with the phenological stages of its host plant L. nanus.

Adult of both sexes had a small thin hair like projection (tail) on each hind wing. Prominent black spots were found near the tail of the hind wings at posterior side. Adults were purplish and covered with long white hairs. A line of brown colour was found towards outer margin of the wings. Lower surface of the both wings were pale grey-brown. A series of whitish spots and bands were found at the marginal side. Hind wing with two eyes pots and a thin hair like projection (tail) on the ventral side (Fig. $1 \mathrm{a}, \mathrm{b})$. According to Fordyce et al.(26) lycaenid butterflies are distinguished by wing pattern, hind wing spots and tail.

During searching the host plants, females vibrated their wings rapidly. They searched by touching the host plant parts and moving forward. After searching the suitable host plant, the female started to lay eggs by bending its abdomen. After laying one egg it took rest for sometimes and then started to lay the next egg. Lampides boeticus laid eggs individually on young shoots, flower buds and leaves of the host plant.

Host plant-parts, viz. flower buds, flower petals, androecium-gynoecium and young pods were consumed as food by different instar larvae. The nature of consumption by the larvae varies in different stages and also in different ways. The volume of consumption was used as area-damaged (flower buds, flower petals, androecium, 
gynoecium and young pods) which was caused by the larvae. According to Roberts some larvae of butterflies feed entirely inside the flowers of Mimosaceae, Fabaceae and Papilionaceae ${ }^{(27)}$.
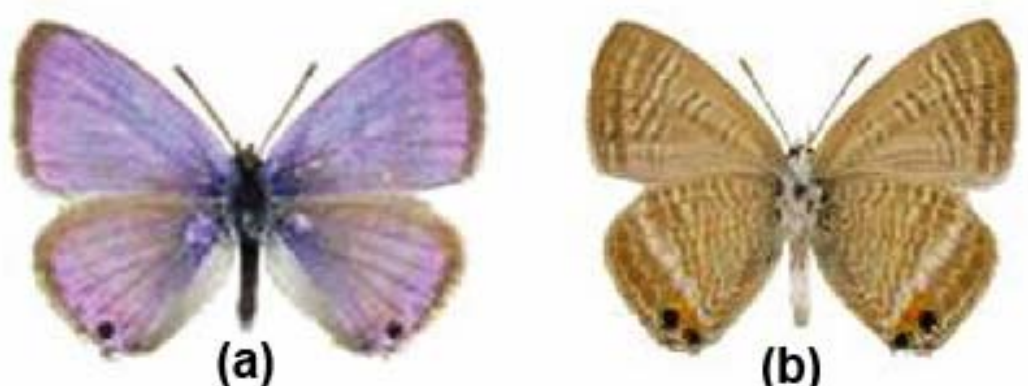

(b)

Fig. 1. External features of adult Lampides boeticus. (a) Dorsal view, (b) Ventral view.

Table 1. Morphometrics of the larvae of Lampides boeticus and its association with the plant parts of Lupinus nanus.

\begin{tabular}{|c|c|c|c|c|}
\hline \multirow[t]{2}{*}{ Larvae } & \multicolumn{2}{|c|}{ Measurement of larval body size } & \multirow{2}{*}{$\begin{array}{c}\text { Morphological } \\
\text { characteristics of larvae }\end{array}$} & \multirow{2}{*}{$\begin{array}{l}\text { Associated } \\
\text { plant parts }\end{array}$} \\
\hline & $\begin{array}{c}\text { Length }(\mathrm{mm}) \\
(\text { Mean } \pm \mathrm{SE})\end{array}$ & $\begin{array}{l}\text { Width }(\mathrm{mm}) \\
(\text { Mean } \pm \text { SE) }\end{array}$ & & \\
\hline $\begin{array}{l}\text { 1st instar } \\
(\mathrm{n}=30)\end{array}$ & $3.56 \pm 0.71$ & $1.51 \pm 0.41$ & $\begin{array}{ll}\text { - } & \text { Cylindrical body } \\
\text { - } & \text { Pale yellow in colour } \\
\text { - } & \text { Black head capsule } \\
\text { - } & \text { Prothoracic shield }\end{array}$ & $\begin{array}{l}\text { FB:+++ } \\
\text { FPT:++ }\end{array}$ \\
\hline $\begin{array}{l}\text { 2nd instar } \\
(\mathrm{n}=30)\end{array}$ & $6.94 \pm 0.92$ & $2.65 \pm 0.54$ & $\begin{array}{l}\text { - Wood-louse like body } \\
\text { - } \text { Pale yellowish brown } \\
\text { colour } \\
\text { - } \text { Reddish band present, }\end{array}$ & $\begin{array}{l}\text { FPT: }++ \\
\text { YP: }++ \\
\text { AG: }+++\end{array}$ \\
\hline $\begin{array}{l}\text { 3rd instar } \\
(\mathrm{n}=28)\end{array}$ & $12.95 \pm 0.73$ & $4.08 \pm 0.47$ & 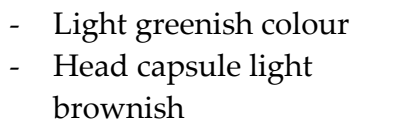 & $\begin{array}{l}\text { FPT: ++ } \\
\text { YP: }++++ \\
\text { AG: }++\end{array}$ \\
\hline $\begin{array}{l}\text { 4th instar } \\
(\mathrm{n}=26)\end{array}$ & $18.06 \pm 0.65$ & $6.08 \pm 0.61$ & 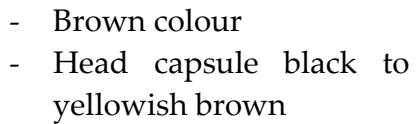 & $\begin{array}{l}\text { YP: ++ } \\
\text { AG: }+++\end{array}$ \\
\hline
\end{tabular}

$\mathrm{SE}=$ Standard error, $\mathrm{FB}=$ Flower $\mathrm{Bud}, \mathrm{FPT}=$ Flower petal, $\mathrm{AG}=$ Androecium and gynoecium, $\mathrm{YP}=$ Young pod. Sign $+=$ Poorly associated (10\%), ++ = Moderately associated (30-50\%), +++ = Highly associated $(70 \%)$ and $++++=$ Deeply associated with host plant (90\% to above). 

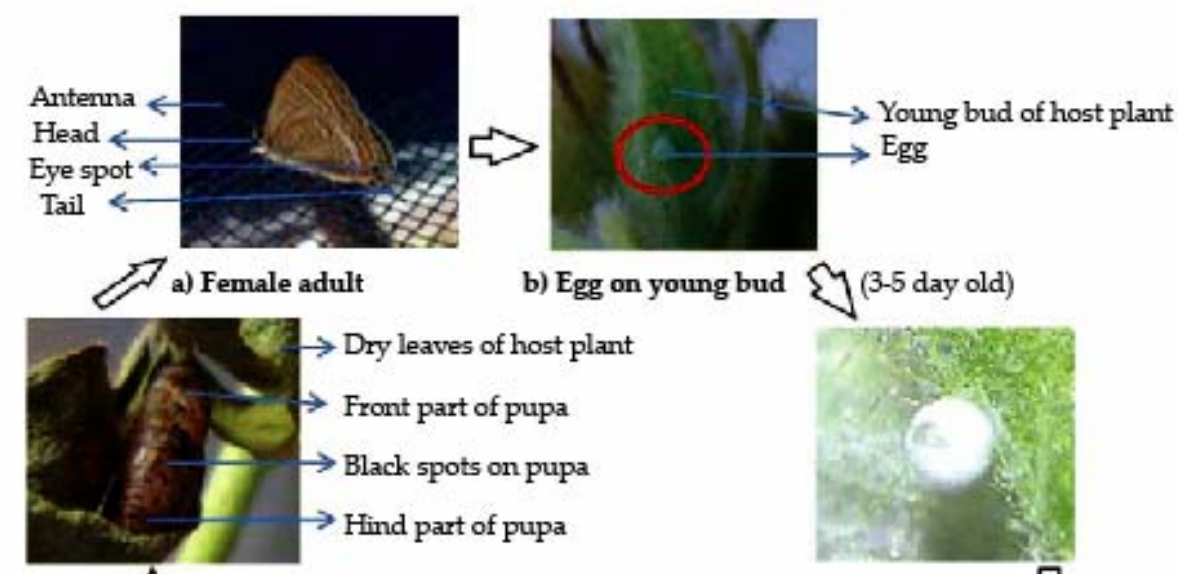
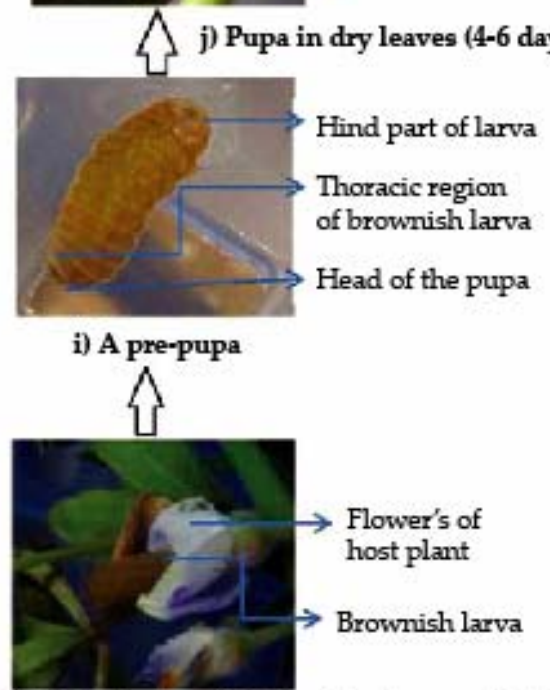

h) 4th instar larva feeding the stamen of plant (3-4 day old) \

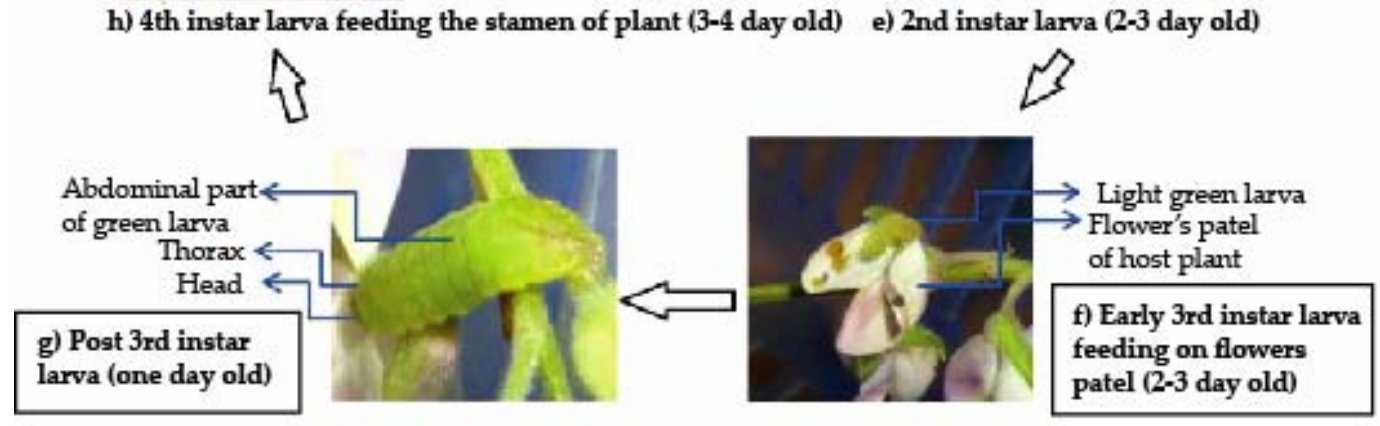

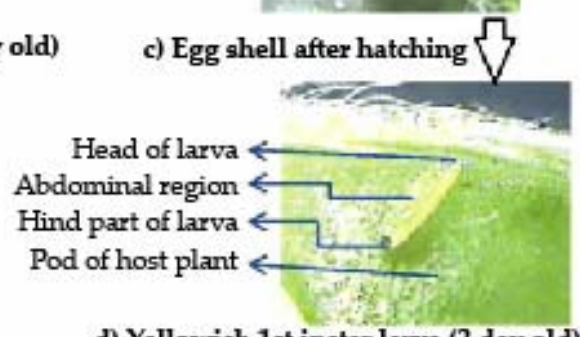

d) Yellowish 1st instar larva ( 2 day old)

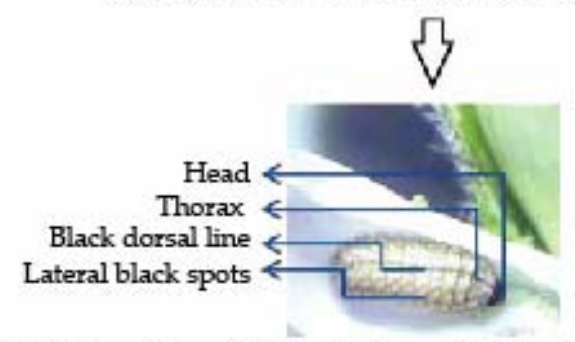

Fig. 2. Developmental stages of Lampides boeticus.

The egg was small and disc-like (about $0.8 \mathrm{~mm}$ in diameter) with a depressed micropylar. When freshly laid, the egg was yellowish green. The surface of the egg was 
covered with a reticulated pattern of ridges (Fig. 2b,c). According to Garcia-Barros and Martinthe(28) shape of the egg is consistent within the main families and differs between other families.

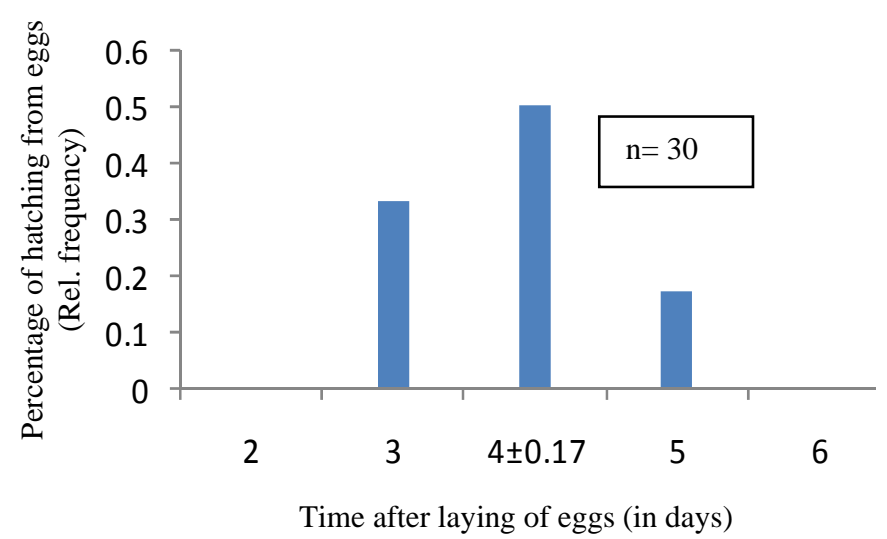

Fig. 3. Temporal duration for the eggs of Lampides boeticus after egg laying.

The mean incubation period of the egg was $4 \pm 0.17$ days $33 \%$ eggs were hatched in 3 days, $17 \%$ in 5 days and $50 \%$ in $4 \pm 0.17$ days, respectively (Fig. 3 ).

After four days, the eggs were hatched into slug-like caterpillars. Average length and width of the 1 st instar larvae were $3.56 \pm 0.17 \mathrm{~mm}$ and width $1.51 \pm 0.41 \mathrm{~mm}$ respectively. The larvae had fine setae on their body. The newly hatched larvae fed on flower bud and started to bore into it (Table 1). Faint reddish brown bands appeared dorsally and laterally of the larvae. The duration of this developmental stagewas 2 days (Fig. 2d).

The body of 2 nd instar larva was woodlouse like in shape. Average length and width of the larvae were $6.94 \pm 0.92$ and $2.65 \pm 0.54 \mathrm{~mm}$, respectively. A reddish brown band was found dorsally on the larva. They maintained the habit of boring into the flower petals and young pods (Table 1).The duration of this developmental stage was 2 - 3 days (Fig. 2e).

Average length and width of the $3^{\text {rd }}$ instar larvae were $12.95 \pm 0.73 \mathrm{~mm}$ and $4.08 \pm 0.47$ $\mathrm{mm}$, respectively. A faint dorsal line was present on the larva dorsally. The light-green colour of the larvae was then changed into green colour. The larvae fed on the young pods of the host plant (Table 1). The duration of this developmental stage was 2 - 3 days (Fig. 2f, g).

Average length and width of the 4th instar larvae were $18.06 \pm 0.65 \mathrm{~mm}$ and $6.08 \pm$ $0.61 \mathrm{~mm}$, respectively. The dorsal line disappeared at the final instar of the larvae. The larvae fed on pods and other flower parts (Table 1). The duration of this developmental stage was 3 - 4 days (Fig. 2h). 
In the final developmental stages of the larvae lengths were measured $18-19 \mathrm{~mm}$ in this period. The larvae were grey in colour. Body of the larvae was gradually shrinked. The larvae ceased eating and wandered around for searching a pupation site. At the chosen site, the larva settled itself for pupation by spinning a silk girdle (Fig. 2i).

Pupation period started after one day of the pre-pupal stage. The lengths of the pupae were 15 - $16 \mathrm{~mm}$. Pupations took place on the dried leaves of the host plant. The hairy pupa had many black to dark brown patches on its body. The Pupae were darkened in colour gradually signaling the imminent emergence of the adult. The duration of this developmental stage was 4 - 6 days (Fig. 2j).

The average pupation period of the pupae was $5 \pm 0.2$ days. $42 \%$ pupae emerged in 4 days, $37 \%$ pupae emerged in 6 days and the rest $21 \%$ pupae emerged in $5 \pm 0.2$ days, respectively (Fig. 4).

The periods of different developmental stages of L. boeticus in its life cycle including incubation, 1st instar, 2nd instar, 3rd instar, 4th instar larvae and pupation were 19, 10, 14, 14, 19 and 24\%, respectively of the total life cycle period (Fig. 5). According to EkAmnuay ${ }^{(29)}$, the life stages of leopard lacewing, Cethosia cyane from egg, larva and pupa usually last for $4-5,15$ - 20 and 7 - 10 days, respectively.

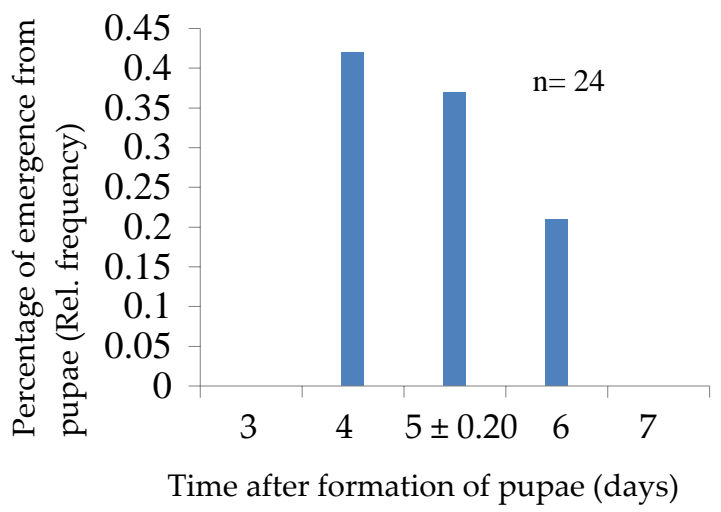

Fig. 4. Temporal duration for the pupae of Lampides boeticus after completion pupations.

The L. boeticus butterfly is closely associated with the phenology of L. nanus (host plant) specially with the young buds, flowers and young fruits (pods).These plants have soft green to grey-green elliptical leaves with palmately-compound leaf blades. The whorled (leaf arrangement) leaves bear silvery hairs. The flowers were produced in dense or open whorls (inflorescence) on an erect spike with a typical legumeflower shape. Flowers were whitish blue in colour. Each lupins flower contains an upper 'standard' or 'banner', two lateral 'wings' and two lower petals which were fused as a 'keel'. The fruitification stage appeared after the flowering stage and lasted before the 
fruits ripen. The fruit was a pod containing several seeds. The legume seeds of lupins, commonly called lupin beans contain significant amounts of isoflavones and toxic alkaloids, e.g. lupinine and sparteine Gladstone et al.(30)(Fig. 6.a,b,c,d).

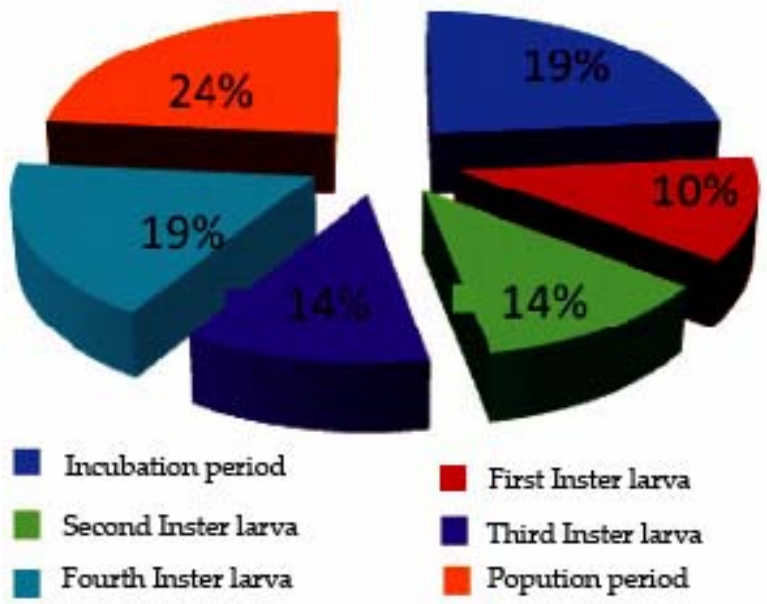

Fig. 5. Time period for each of the life stages of Lampides boeticus (in percentage) of its life cycle.

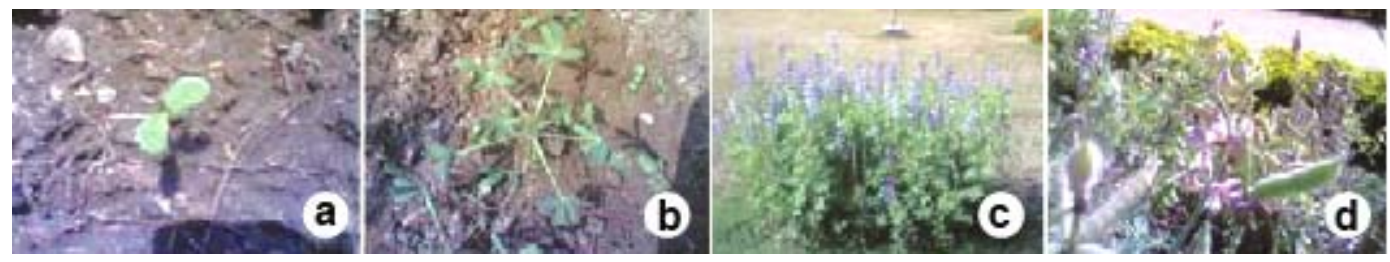

Fig. 6. Phenological stages of Lupinusnanus (host plant). (a) Germinating stage, (b) vegetative growth, (c) flowering stage and (d) fruitification stages.

There is synchronization between the host plant's (Lupinus nanus) phenology and the developmental stages of the butterfly. Characteristically variations are found in the consumption of the host plant-parts (flower buds, flower petals, androecium gynoecium and young pods) by the larvae of $L$. boeticus. The consumption of the plant parts was found to increase from the larval 1st instar to the 3rd instar stages. But, comparatively the consumption of the plant parts was found to decrease during the 4th instar stage. This happened due to the changes required by the ultimate instar to go for prepupal stage.

Coincidences between plant reproductive stage especially fruitification and developmental stages of the butterfly were distinct. All the larval stages of the butterfly were associated with the flowers and young fruits of the host plant parts from young buds to young fruits (pods) as food sources. This coincidence between plant and animal is essential for the completion of their life history successfully. This is co-evulutionary in 
one hand for the larval development of the insect (butterfly), and on the other hand for the gene flow activities of the plant.

\section{References}

1. Thomas CD and HC Malorie 1985. Rarity, species richness and conservation: Butterflies of the Atlas Mountains in Morocco. Biological Conservation 33: 95-117.

2. Pollard E and TJ Yates 1993. Monitoring Butterflies for Ecology and Conservation. Chapman \& Hall. London. pp. 443.

3. Scoble MJ 1992. Form, Function and Diversity. Oxford University Press, New York. pp. 253.

4. Bashar MA, MA Mamun and SM Rahman 2005. Wing-venation as a factor for the identification of pierid butterflies in the forests of Bangladesh. Bangladesh J. Zool. 33(1): 49-56.

5. Pianratna A and JN Eliot 1985. Butterflies in Thailand. Viratham Press, Bangkok. pp. 235.

6. Leps J and K Spitzer 1990. Ecological determines of butterfly communities (Lepidoptera, Papilionidae) in the Tam Dao Mountains, Vietnam. Acta Entomologica Bohemoslovaca 87: 182-194.

7. Molina JM and JM Palma 1996. Butterfly diversity and rarity within selected habitats of Western Andalusia, Spain (Lepidoptera: Papilionidae and Hesperioidae). Nota Lepidopterologica 78: 267-280.

8. Bashar MA, F Begum and S Bilkis 2013. Involvement of local people and their culture of undergrowth cut in deforestation process of rain forest in the district of Chittagong and Cox's bazar. (Submitted in oriental photographer, Dhaka Univ., Dhaka, Bangladesh).

9. Sharp MA, DR Parks and PR Ehrlich 1974. Plant resources and habitat selection. Ecology 55: $870-875$.

10. Courtney SP 1986. The ecology of Pierid butterflies: dynamics and interactions. Adv. Ecol. Res. 15: 51 - 116.

11. Price PW, GW Fernands, TM Lewinsohn and WW Benson 1991. Plant - Animal Interactions. John Willey and Sons Inc. pp. 39.

12. Barua KK and J Slowik 2007. Study on the biology and consumption potential of Common Rose, Pachlioptaaristolochiae aristolochiae F (Lepidoptera: Papilionidae) on Aristolochia tagala. Polish J. Ent. 76: 341-352.

13. Boggs CL 1987. Ecology of nectar and pollen feeding in Lepidoptera. Nutritional Ecology of Insects, Mites, Spiders and Related Invertebrates.Wiley, New York. pp. 369 - 391.

14. Porter K, CA Steel and JA Thomas 1992. Butterflies and Communities. The Ecology of Butterflies in Britain. Oxford University Press, New York. pp.139-177.

15. Rusterholz HP and AN Erhardt 1999. Can nectar properties explain sex-specific flower preferences in the adonis blue butterfly Lysandrabellargus? J. Ecol. Ento. 25(1): 81-90.

16. Jermy T and A Szentesi 1978. The role of inhibitory stimuli in the choice of oviposition site by phytophagous insects. Appl. Ent. Exp. 24: 458-468.

17. Bashar MA, N Parveen and MAK Chowdhury 2008. Case-making insect pest (Sinclita occidentalis: Pyralidae) and its characteristics association with duckweeds in minipond ecosystem. Dhaka Univ. J. Biol. Sci. 17(2): 109-118. 
18. Zalucki MP, AR Clarke and SB Malcolm 2002. Ecology and behaviour of first instar larval Lepidoptera. Annual Review of Entomology 47: 361-393.

19. Singh I and G Singh 1993. Assessment of foliage loss caused by different larval instars of Bihar hairy caterpillar, Spilosoma obliqua (Walker) on sunflower. J. Insect. Sci. 6(2): 185-186.

20. Baker RR 1984. The Biology of Butterflies. Royal Entomological Society of London. Academic press, London, UK. pp. 279-296.

21. Rao ARK, TM Krishna, SVRK Rao, BC Reddy, KH Babu and LK Gopal 2006. Studies on morphometrics and biology of citrus butterfly Papiliodemoleus Linnaeus (Lepidoptera: Papilionidae) on acid lime, Citrus aurantifolia Swingle. Entomon. 515: 630-640.

22. Hill CJ 1989. 1. The effect of adult diet on the biology of butterflies. 2. The common crow butterfly, Euploea corecorinna. Oecologia 81: 258 - 266.

23. Borror DJ, DM Delong and CA Triphlehorn 1981. An Introduction to The Study of Insects. $\left(5^{\text {th }}\right.$ edition). CBS College Publishing. New York. pp. 476- 549.

24. Bingham LCT 1905. The Fauna of British India (Vol. I). Toylor and Francis,London. pp. 511.

25. Pandey BP 1969. Taxonomy of Angiosperm. Rajendra Rabindra Printers Ltd., Ram Nagar, New Delhi. pp. 98-344.

26. Fordyce CC, ML Forister and AM Shapiro 2002. The significance of wing pattern diversity in the Lycaenidae: Mate discrimination by two recently diverged species. J. Evol. Biol. 15: 871-879.

27. Roberts TJ 2001.The Butterflies of Pakistan. Oxford University Press, UK. pp.122-157.

28. Garcia-Barros E and J Martin 1995. The Eggs of European Satyrine butterflies (Nymphalidae): External morphology and its use in Systematics', Zool. Jour. Linnean Soc. 115(1): 73-115.

29. Ek-Amnuay P 2006. Butterflies of Thailand (Vol. 2). Baan LaeSuan, Bankok. pp. 36.

30. Gladstone JS, CA Alkins and J Hamblin (ed) 1998. Lupins as Crop Plants: Biology, Production and Utilization. PAB International, Wallingford UK pp. 1-353. 